\title{
Digital technologies in higher education: Learning Challenges
}

\author{
by \\ Fayiz Aldhafeeri (Kuwait University) \\ \& \\ Trevor Male (UCL Institute of Education)
}

\section{Introduction}

This entry explores the use of digital technologies in higher education. There is now widespread recognition that in the $21^{\text {st }}$ Century digital technologies, particularly portable hand-held devices capable of Internet connection, present opportunities and challenges to the way in which student learning is organized in schools, colleges and institutions of higher education. Traxler (2010) suggests such devices are pervasive and ubiquitous, conspicuous and unobtrusive, noteworthy and taken-for-granted with everyone typically owning one, using one and often having more than one. Consequently, it has been argued that the availability of such devices, controlled mainly by the student and not the teacher, has the potential to change the traditional dynamics and pedagogical patterns of the learning environment (Burden et al, 2012). Education institutions, however, typically remain organized around spatial and temporal considerations such as buildings, timetables, calendars and internal structures with student learning environments still bearing a worrying correspondence to those used in the previous two centuries.

The principal concern to arise is a need to reconfigure the role of the teacher and their relationship with the student, with the balance of arguments seen in relevant literature indicating a need to provide the learner with greater control in a digitally enhanced environment. Traditional teacher led environments, it is concluded, should move from direction and control to facilitation and guidance of learners, a process requiring new skills 
and knowledge on behalf of staff charged with leading student learning. This has been described as the transition of teacher from "sage on the stage, to guide on the side" (King, 1993: 30).

\section{Digital technologies and learning in higher education}

The term 'digital technologies' in this study refers primarily to multi-functional equipment or devices with Internet connectivity and particularly to devices that are hand-held and portable, a definition which generally means smart-phones and tablet computers. In exploring the opportunities offered through the combination of more traditional Internet access (fixed location) and personal Internet access (mobile) several trends have been identified which institutions of higher education need to explore, evaluate and possibly adopt as they move forward in a new era. The principal focus of this entry is to explore how student learning could be enhanced through use of appropriate digital technologies.

With portable digital devices now being a core feature of the $21^{\text {st }}$ Century this presents the possibility for a fundamental change to education, shifting from passive acquisition of someone else's ideas to active learning experiences that empower people to inquire, critique, create, collaborate, problem solve, and create understanding (Dede \& Barb, 2009). With new technologies information is continually being developed, distributed and acquired and has become a paradigm that cannot be ignored within educational organizations. Selwyn (2007: 91) makes the case that these digital technologies could allow institutions of higher education to reinvent themselves, requiring institutions to make a shift "from the representational capabilities of ICTs (i.e., their ability to represent commoditized informational delivery modes of higher education) to their more expansionist and relational potentials"'. In examining these changes, the American Society for Training and 
Development (2009) not only reflected the way in which the 'millennials' (those born between 1977 and 1997) approach learning, but also identified the need to incorporate these digital technologies into the workforce of the future:

The online world has redesigned communication in and outside the workplace; anyone can access almost anything about a topic, so [young people] are now accustomed to accessing mutliple open sources of information for solutions. As a result there are more collaborative technologies that have enabled the learning process to evolve from a fixed series of discrete training events into an informal, ongoing experience. Learning can easily occur anytime, anywhere and in a variety of formats. ( $p 3)$

Digital technologies thus offer the potential for different forms of learning and teaching where academic staff and students can change or transform their perspectives and meanings. The 'push-pull' architecture of the Internet invites participation, generating symmetry between production and consumption which is not evident in traditional 'broadercasting' mediums such as television or traditional models of formal learning. Tools such as wikis, social networking software (e.g. FaceBook) and aggregator services (sites which bring together artefacts from other places) are identified as how educators might shift the emphasis of their teaching by empowering the student to see themselves as knowledge coconstructors rather than passive recipients of information provided. In an era when knowledge is no longer fixed and is subject to challenge on the very public platform of the Internet students need the skills to explore and synthesize data to determine knowledge and construct meaning.

In this emerging digital age models of learning based on behaviourism, cognitive, constructivist and co-constructivist approaches are being overtaken by connectivism, an approach first offered by Siemens (2009). Connectivism defines learning as a continual process which occurs in different settings, including communities of practice, personal networks and work places and allows teachers to shift focus from their textbooks and 
presentation to the actual student. Knowledge is emphasized by this theory, which stresses the need to help students gather, access, synthesize and publish knowledge in print or in online media. This knowledge is no longer under the control of experts, but has been distributed and is accessible to average students. In connectivist-based learning, the role of the teacher changes from that of providing material and presenting lectures to one of helping students create, publish and share knowledge using Internet-based technologies. Consequently, connectivism suggests giving the learner the control to explore objectives defined by that learner. To facilitate the interaction both synchronous and asynchronous tools are essential as extensions of course environments. With connectivisim, active participation is required by all involved in the learning process and matches the aspirations offered by Confucius: "Tell me, and I will forget; show me, and I will remember; involve me, and I will understand."

Based on the above discourse we devised a model which seeks to guide learning in higher education beyond self-managed learning and, in this instance, an approach to student learning that makes full use of digital technologies (see Figure 1, below). As Crook (2008) indicates, the learning process in higher education requires greater self-management of learning as students progress from entry stage to graduation and on to postgraduate level and, in a digital age, engage with fellow students in a collaborative mode. We argue that in addition student learning potential will be enhanced by use of digital technologies that are now readily available and foresee the ultimate aim of such education as being the creation of effective learning environments through interdependency, a state often seen as ideal in the world of work where problem solving and creativity are the product of collaboration rather than independent contributions as suggested earlier (Helfand, 2013). 
Interdependency is highly valued in the workplace where, within a couple of decades, the tools used in most occupations will be replaced by digital ones (Organisation for Economic Cooperation and Development, 2015) and in situations where it is essential that "young people can demonstrate that they not only possess knowledge demanded by employers, but that they can apply that knowledge in different and unfamiliar circumstances" (Mann and Huddleston, 2015: 7: original emphasis).
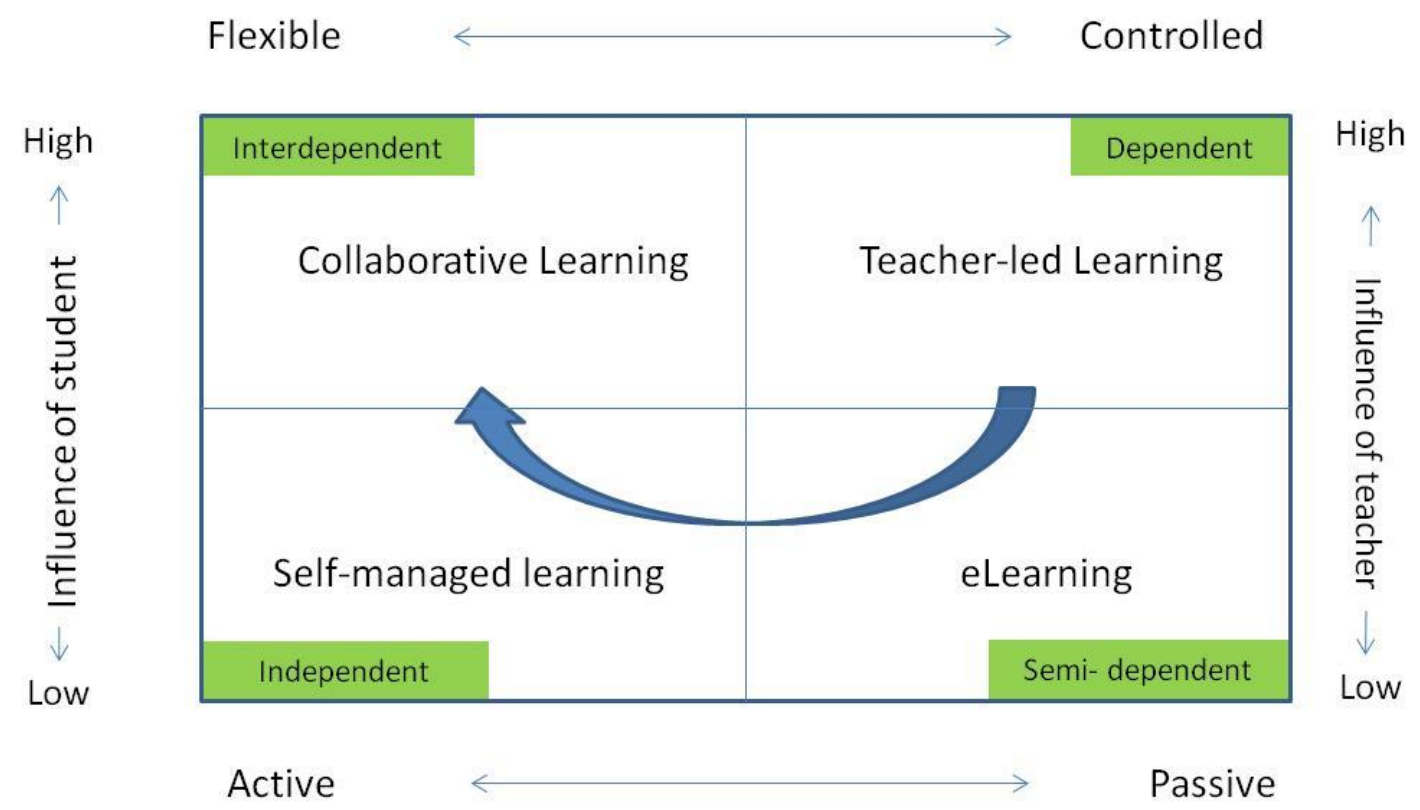

Figure 1- Learning in a Digital Age - Aldhafeeri \& Male (2015)

\section{Use of Digital technologies in Kuwait University}

In a previous study students and faculty teaching staff from the College of Education in Kuwait University were surveyed to assess their access to digital technologies, their capability to use them effectively in support of achieving planned learning outcomes and the implications for change that could emanate from such findings (Aldhafeeri \& Male, 2015). Kuwait University Is comparable to other institutions of higher education across the world in that most student learning is organized around face-to-face taught sessions with an 
expectation that students will undertake further study as appropriate in non-contact times. The organization of student learning in the university tended to follow traditional models, therefore, with academic staff presenting knowledge for student consumption via lectures, seminars and directed reading. Whilst there was widespread use of computer technology in the university in terms of support for learning this equipment typically was only used for presentation of material during taught sessions or as a repository for materials through use of a virtual learning environment (VLE). Meanwhile most members of the university had ready access to digital technologies, particularly portable hand-held devices capable of Internet connection, and were very capable of using them in a personal capacity.

Interestingly, academic staff not only exhibited a higher level of ownership of personal mobile digital devices than the student body, but also perceived themselves to be at least as capable as students in the use of such equipment to support teaching and learning in the college. Students, on the other hand expressed doubt on the claims made by academic staff of competency and regularity of use of computer technologies in support of learning. A typical taught session, they claimed, consisted of lecturing and discussion without use of technology. The truth seems to be that whilst academic staff may be skilled and competent in the use of technology at a personal level it was still not used extensively in face-to-face learning. Furthermore, use of personal devices was not allowed during lectures, even for Internet searches for relevant materials. The scenario witnessed in Kuwait is almost certainly mirrored across the world's universities.

\section{Discussion \& Conclusions}

Our previous work suggests that in the current era higher education academic staff and students are well equipped with personal mobile digital devices and generally consider 
themselves to be competent users of such equipment and associated software applications in their personal life. There was little evidence, however, to suggest extensive use of digital technologies to enhance student learning, often with the use of portable digital devices being actively discouraged in taught sessions.

The conclusion to draw from our study in Kuwait University is that ineffective use of available digital technologies is probably more to do with attitude rather than lack of opportunities. The findings from that study seem to mirror the situation that seemingly permeates all phases of education globally in that the technology exists, as does the capability to use it, but the willingness to exploit personal mobile digital devices and associated software applications is limited. The source of such limitation is typically based around intransigence of teaching staff to adapt their practice, a response often disguised through concerns about student safety and the validity of data sources when using the Internet (see, for example, Male \& Burden, 2014).

As discussed above, however, the potential use of digital technologies in higher education is evolving rapidly and, in the light of globalisation and employability, this introduces an imperative for review and change of personal practice and organisational structures to accommodate new possibilities. Higher education institutions in the $21^{\text {st }}$ Century will need to adapt their strategy and policy regarding student learning to accommodate greater use of personal mobile digital technologies not only because they exist, but also in recognition of the opportunities to provide deeper, collaborative learning amongst students in the quest to further knowledge. Higher education should not be immune from such influences, but will need to take suitable action soon if it is to fulfil its ambition to provide its student body with the knowledge and skills to operate successfully in the digital era. 


\section{References}

Alhafeeri, F. and Male, T. (2015). Investigating the learning challenges presented by digital technologies to the College of Education in Kuwait University. Education and Information Technologies, 21(6), 1509-1519.

American Society for Training and Development (2009). Transforming learning with Web 2.0 technologies. ASTD Research: Virginia, USA.

Burden, K., Hopkins, P., Male, T., Martin, S. and Trala, C. (2012). iPad Scotland evaluation. Hull: University of Hull.

Crook, C. (2008). Web 2.0 technologies for learning: The current landscape Opportunities, challenges and tensions. London: BECTA Research Reports.

Dede, C. and Barb, S. (2009). Emerging technologies for learning science: A time of rapid advances. Journal of Scientific Educational Technology, 18: 301-304.

Helfand, D. (2013). Watering the roots of knowledge through collaborative learning. Chronicle of Higher Education. Available at: https://chronicle.com/article/Watering-theRoots-of/140135/ - Accessed 29 October, 2019.

King, A. (1993). From sage on the stage to guide on the side. College Teaching, 41(1), 3035 .

Male, T. and Burden, K. (2014). Access denied? Twenty-first century technology in schools. Technology, Pedagogy and Education. 23(4), 423-437.

Mann, A. and Huddleston, P. (2015). How should our schools respond to the demands of the twenty first century labour market? Education and Employers Research: Occasional Taskforce Research Paper 4: February.

Organisation for Economic Cooperation and Development (2015). Students, computers and learning: Making the connection. Available at: http://dx.doi.org/10.1787/9789264239555en, accessed 29 October, 2019.

Selwyn, N. (2007). The use of computer technology in university teaching and learning: A critical perspective. Journal of Computer Assisted Learning, 23, 83 -94.

Siemens, G. (2009). Connectivism: A learning theory for the digital age. Available at: https://jotamac.typepad.com/jotamacs weblog/files/Connectivism.pdf, accessed 29 October, 2019.

Traxler, J. (2010). Will student devices deliver innovation, inclusion and transformation? Journal of the Research Centre for Educational Technology, 6 (1), 3-15. 